\title{
Reputation Management System for Fostering Trust in Collaborative and Cohesive Disaster Management
}

\author{
Sabeen Javed, Hammad Afzal, Fahim Arif \\ National University of Sciences and Technology \\ Islamabad, Pakistan
}

\author{
Awais Majeed \\ Bahria University \\ Islamabad, Pakistan
}

\begin{abstract}
The best management of a disaster requires knowledge, skills and other resources not only for relief and rehabilitation but also for recovery and mitigation of its effects. These multifaceted goals cannot be achieved by a single organization and require collaborative efforts in an agile manner. Blind trust cannot be applied while selecting collaborators/team members/partners therefore good reputation of a collaborator is mandatory. Currently, various Information and Communication Technology based artifacts, for collaborative disaster management, have been developed; however, they do not employ trust and reputation as their key factor. In this paper, a framework of reputation based trust management system is proposed for the support of disaster management. The key features of framework are Meta model, Reputation Indicator Matrix and Computational algorithm, deployed using Service Oriented Architecture. To evaluate the efficacy of the artifact, a prototype is implemented. Furthermore, an industrial survey is carried out to get the feedback on the proposed framework. The results support that the proposed reputation management system provides significant support in collaborative disaster management by assisting in agile and smart decision making in all phases of disaster management cycle.
\end{abstract}

Keywords-reputation; trust; reputation management; disaster management; collaborators; collaborative management

\section{INTRODUCTION}

Trust is such an investment in a society that returns strong and peaceful society whereas reputation is an asset that makes social interactions smooth and comfortable. The importance of trust and management in society, particularly in a disaster and emergency situation, cannot be ignored as managing such situations demands the collective role of a society. The stakeholders involved in such situations focus on the cohesive and collaborative efforts. These collaborative efforts demand sharing of skills, knowledge and other financial resources. It is also evident that collaborators involved in disaster management have different cultural, social and organizational background which may obstruct the efforts of collaboration.

Sharing of resources and skills in other domains like egovernment, e-commerce and e-business, is made possible through Virtual Organization (VO), a form of collaborative networks. The focal point of $\mathrm{VO}$ is doing tasks and projects together by making collaboration among a number of entities, and ensuring agility [1]. It is a successful experiment for accomplishing the required goals by making a temporary alliance of partners [2] and the reason of its success is the opportunity of cohesive and collaborative efforts, it provides.
Many Information and Communication Technology (ICT) based solutions for collaboration have been developed. These solutions have not only facilitated the $\mathrm{VO}$ form of collaboration in e-commerce and e-government but also in social networks. Moreover, to facilitate the collaborative and cohesive efforts for disaster management, several ICT-based solutions like SAHANA [3] and Oasis [4]are developed. These systems were more focused on considering the agile collaboration of VO, however, reputation and trust were not much focused in these systems. Since collaborative efforts engage precious resources, therefore, the role of trust and reputation becomes vital. Neither an organization nor a government can put a blind trust in anyone when there are issues of saving human lives and utilization of precious resources. Therefore, it is apparent that reputation based trust is such a building block of disaster management, without which the goal of efficient disaster management cannot be achieved in its true essence.

It is recognized that in ICT, considerable importance to the reputation of collaborators for disaster management is not given and the solutions presented in other domains cannot be directly applied to disaster management, keeping in view the dynamic context of trust.In this research, a conceptual framework for disaster management is proposed that lays emphasis on reputation and trust. The framework includes indicators/factors, having impact on the reputation of collaborators. These indicators/factors are extracted and deduced from the existing extensive literature available on disaster management. We have also gathered the requirements from stakeholders which are working in this domain. An algorithm to calculate the reputation score of collaborators/partners is proposed. Moreover, software architecture for reputation based trust management system is also proposed that helps in the exchange of required information among the heterogeneous systems of disaster management organizations/agencies. Using this heterogeneous platform, disaster management agencies will be able to get support in more collaborative and efficient. We have conducted a field survey involving a number of large and effective organizations involved in disaster management. The results of survey, on one hand, demonstrate the efficacy of our proposed framework.

The structure of rest of the paper is as follows: Section 2 provides a detailed literature review comprising some of the basic definitions such as Trust and Reputation Management, followed by related work in the field including Feedback Aggregation Models and existing ICT based Disaster 
Management Systems. Proposed Framework is presented in Section 3, followed by implementation details. Finally, evaluation and results of survey are presented followed by conclusions.

\section{LITEARTURE REVIEW}

This section reviews the state of the art in the domain of trust, reputation, reputation management system, disaster management and virtual organization. Moreover, the applicability of VO to disaster management is discussed.

\section{A. Trust}

Trust is an uncertain situation, faced by an individual, in which beneficial or harmful result is reliant on the other person's behavior. Deutch defines trust as the situation when an individual faces an ambiguous path in which the outcome is either beneficial or harmful depending on the behavior of another person[5]. The nature of trust is identified as dynamic in context[6]. Considering this characteristic, several trust management systems(applicable to different domains) have been developed. These systems are either reputation-based or policies-based. For reputation-based systems, trust is evaluated on the history of performance or interaction whereas for policy-based systems, trust assessment is based on credentials for issuance of access[6]. Furthermore, trust has three properties; identification, qualification and consistency. Identification includes traditional encryption and authorization; Qualification checks and analyze whether the subject entity has the required criteria; and Consistency, the most difficult one, is checked through formal certification or feedback [7, 8]. In another study[9], Gallivan classified trust into following five types.

1) Knowledge based trust is attributed with previous performance history of the subject entity.

2) Swift trust builds quickly within temporary teams. It is recommended when temporary teams have to achieve critical goals in short time.

3) Characteristic based trust is based on the qualities of the subject entity.

4) Institutional based trustdevelops with the help of guarantors.

5) Justice based trust illustrates procedural justice that is ensured through fair procedure.

\section{B. Reputation and Reputation Management Systems}

Reputation is the evaluation of trustworthiness of an entity that it can perform a task. A reputation system manages the reputation of entities [10]. Reputation is calculated based on the feedback of associative entities and assists in developing trust among the community/team members. Due to this, reputation based trust is given vital importance in virtual communities like social networks and e-commerce. Several reputation based trust management systems have been developed in different domains that facilitate the relevant authorities in decision making in different contexts.Amazon[11], epinions and eBayuse web based reputation systems. For reputation management, multi-criteria assessment approach is proposed by [2].

\section{Feedback Aggregation Models}

Feedback aggregation models are an integral part of reputation systems. These models help in aggregating and compiling feedback score obtained from different internal and external sources to produce a cumulative reputation score. Table 1 shows different types of feedback aggregation models with examples as described in[10].

TABLE I. Types of FeEdBack Aggregation Models

\begin{tabular}{|l|l|l|}
\hline $\begin{array}{l}\text { Models/ } \\
\text { Network Type }\end{array}$ & Reputation Calculated through & Examples \\
\hline Sum and Mean & $\begin{array}{l}\text { Summation and then } \\
\text { normalization through mean }\end{array}$ & $\begin{array}{l}\text { Amazon, eBay and } \\
\text { epinions }\end{array}$ \\
\hline Flow Network & Transitive iterations & Google's PageRank \\
\hline Markov Chain & Weighted Directed Graph & PowerTrust \\
\hline Fuzzy Logic & Describe linguistically & REGRET \\
\hline Bayesian & Probability Distributed Function & - \\
\hline
\end{tabular}

\section{Importance of Trust in Collaborative Disaster}

\section{Management}

Collaborators have different cultural and organizational background, therefore, trust and reputation become important for effective collaboration. This understanding persists in the disaster management stakeholders and is identified in [12]. The author presents trust as a key element in quickly formed teams for DM. Considering the quick formation of emergency respondent teams, their study identified that swift trust is a key to achieve strong collaboration in quickly formed temporary teams.

Another study [13], carried out after 9/11 attack, identified that Trust is catalyst for effective collaboration in disaster management. Their work was carried out to reveal the causes behind the lack of unified command during the incident. The author suggested that multi-disciplinary training and education, through exercises, drills and other means, can improve the disaster management. The author also recommended that the mechanism for comprehensive and timely information sharing among the respondent agencies must be in place. Besides this, the formation of joint operation teams also improves the inter-agency collaboration. The author suggested that these are the ways for developing an understanding of the respondent agencies' culture, improve information sharing and enhanced integrated response.

In another research[14], the importance of inter-agency cooperation, during a disaster and emergency situation, was evaluated. It was explored that working together for managing disasters in an influential way greatly depends on the trust among the team members. It was also recognized that training through drills and other means also enhances the skills and knowledge of the respondents. This research also suggested that the use of ICT can improve the information sharing process. Realizing the importance of trust in DM, an information repository framework for emergency response information system was proposed in[15]. Risk engine is also incorporated in this framework for evaluating any kind of risks involved for decision maker. This is a generalized model and ignores the dynamic contextual nature of trust. 


\section{E. DM Collaboration through ICT-based Solutions}

An Emergency Management Accreditation Program (EMAP) identifies thirty categories for emergency response operations. Twelve categories require collaborative and cohesive efforts. These categories are mass sheltering, human services, public health and medical services, debris management, population protection, restoration of transport system, fatality management, fire protection, donation management, resource management, public works\& engineering and damage assessment.To handle the tedious tasks of disaster management, disaster management cycle is divided into four phases[16]:

1) Preparation and Planning: contingency plans are made and actions are defined for any expected disaster in this phase.

2) Response: this phase depicts all the operations that are carried out immediately after a disaster comes.

3) Recovery: it includes all the actions that are carried out to recover the infrastructure and the routine life.

4) Mitigation: actions are taken to alleviate and lessen the effects of a disaster.

By understanding the importance of cohesive and collaborative efforts in DM, various ICT-based solutions are developed for efficient disaster management. SAHANA and OASIS are two examples of it.Open Advance System for disaster and emergency management (OASIS)[16] is a cofunded project by European Commission. The purpose of this project is to facilitate the communication, collaboration and decision making in a disaster and emergency situation. Three hierarchical (strategic, operational and tactical) levels are defined for OASIS along with various other modules like IT Framework, Operational Tools and Tactical Situational Object (TSO)[17]. Moreover, OASIS also resolves the interoperability and security issues that can be faced by legacy IT systems. SAHANA is an open source disaster management system. It has various modules like Organization Registry, Missing Persons Registry, Request Management System, Volunteer Management, Shelter Registry, Situation Awareness and Inventory Management[3]. SAHANA has been deployed in various disaster situations and has proved to be a good facilitator in managing disasters.

\section{F. VO and its Applicability to DM}

$\mathrm{VO}$ is a temporary alliance of companies that can quickly share their core competencies to exploit the market opportunities[2]. This coalition forms another organization where company's boundaries are smudged. The advantages over the conventional way are the agility, the disperse-ability of collaborators, the integration of resources and the digitization of whole process [1]. For reputation building and managing, the approach of multi-criteria assessment is used in[2]. The lifecycle of VO consists of four phases:

1) Identification: goals and objectives are identified.

2) Formation: collaborators are evaluated and selected.

3) Operational: to meet the goals and objectives, operations are carried out by the selected collaborators.

4) Dissolution: when goals are met, temporary alliance is dissolved.

The stakeholders, involved in disaster management, recognize and admit that neither a government nor an organization can handle large-scale disasters on its own; therefore it is the responsibility of each individual and each organization to play its role collectively. Since VO also focus on the collaboration among a number of organizations/ collaborators and doing tasks together by introducing agility in the process; therefore, this concept seems applicable to DM.

\section{PROPOSED FRAMEWORK}

The proposed framework focuses on the reputation based trust management of collaborators involved in disaster management operations. This framework has three main characteristics: (i) it is applicable to all phases of disaster management cycle. (ii) it is applicable to the operational categories (defined in EMAP) that need collaboration. (iii) it is applicable to three hierarchical levels which are defined in the OASIS i.e. reputation can be managed at these three levels. The framework consists of four components:

1) Meta model for Reputation Indicators (RI)

2) Reputation Indicator Matrix

3) Computational Algorithm for Reputation Calculation

4) Service Oriented Architecture (SOA) for information extraction and exchange.

Further details of these components are described below:

\section{A. Meta Model for Reputation Indicators}

The first component of our framework provides the Meta model for reputation indicators. This Meta model consists of indicator/factors/criteria having impact on the reputation based trust of the collaborators. These factors are deduced from framework, protocols, standards and other published work of disaster management. The deduced factors are related to the operational categories defined in EMAP. Our meta-model divides these factors into two categories based on the four phases of disaster management cycle. The first category is called 'Pre-disaster' whereas other is called 'During \& Post/After disaster'. Both categories consist of nine factors each. Our proposed Meta model is shown in the Fig. 1. 


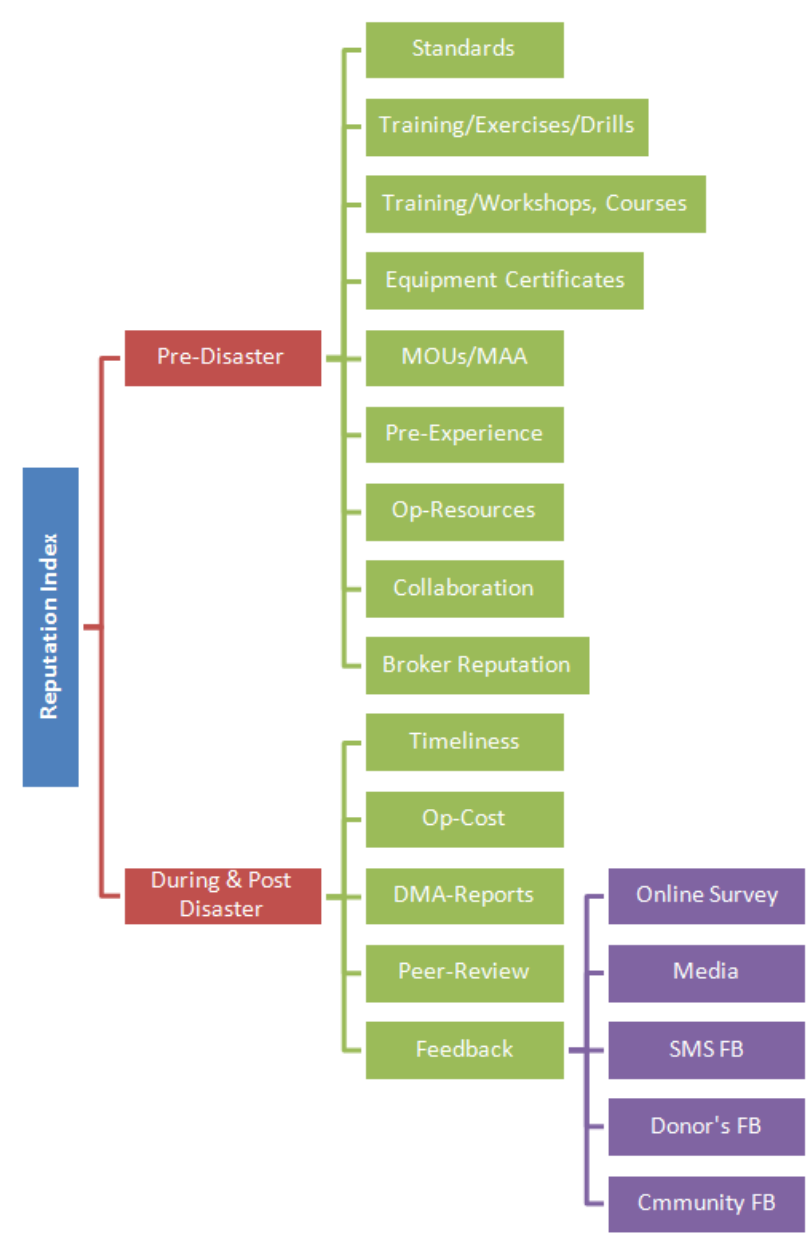

Fig. 1. Proposed Meta Model for Reputation Indicators

Meta model for reputation indicators consists of factors/indicators having impact on the reputation of collaborators. These indicators are extracted from the literature of disaster management and briefly discussed here.

Standards: Various standards (like Humanitarian Accountability Partnership and SPHERE) for managing disasters are developed. These standards are defined and developed by different disaster management stakeholders and ensure quality of humanitarian services. The organizations that follow such standards are considered trustworthy as it shows their level of preparedness.

Training: Training/educating of collaborators is considered extremely important for disaster management. The training can be either in the form of Courses/Workshops or in the form of Drills/Exercises. To make awareness among the collaborators, workshops and training courses for disaster management are important. Similarly, Drills and Exercises are meant to train the people/organizations for an emergency and disaster situation. The other purpose for this factor is to give them an opportunity to do coordinative efforts so that trusting relation can be built among themselves. Organizations like United Nations International Strategy for Disaster Reduction (UNISDR), National Disaster Management Authority (NDMA) of Pakistan and Federal Emergency Management Agency (FEMA) of United States regularly organize such exercises and drills. Moreover, these organizations also conduct workshops and offer courses to make awareness about disasters.

Collaborations: Collaborators, that have participated in their related operational category in a past disaster and performed better, are also trustworthy. Organizations having local or international collaborations with other disaster management organizations are also considered to be trustworthy.

Previous Experience: A collaborator's previous experience, in their related operational category, is also an important factor to evaluate their competency.

Broker Reputation is another concept that can assist in evaluating the reputation of collaborators. This concept is applied in ICT solutions developed for other domains like ecommerce and social networks. Broker reputation management system gives the details about the reputation of the collaborator under consideration. It is helpful to consider this reputation.

Operational Resources depict the competency of the collaborators. The quality and quantity of these resources play important role in a disaster situation. This factor is given considerable importance in the framework of NDMA and Hyogo. Memorandum of Understandings (MoUs) and Mutual Aid Agreements (MAAs) form another group of criterion that is regarded as significant in disaster management.

The second category of Meta Model helps in evaluating the reputation of the partner after they have performed on ground. In other words, this category considers the performance history of the collaborators. For this, operational costs and timeliness are key factors as efficient usage of resources and agile response are mandatory in a disaster situation. Besides this, Disaster Management Agency's report about the collaborator's performance is also important. Peer's reviewabout its partner is also significant in establishing the reputation. Feedback from other stakeholders can also be an important tool for evaluating the reputation of the collaborators. These stakeholders include affected population, media, donors and different communities. The tasks and projects which are funded by various donor organizations should be monitored. To make it transparent, donors' feedback is important to establish the good reputation of the disaster management agency and its collaborators. Peers can also review their colleagues as they have worked on ground with them. Media reports are also important. Feedback by various communities is also required to evaluate the reputation of collaborators. In this regards, professionals, students and other volunteers can better evaluate the collaborators. Similarly, online survey and SMS feedback from affected population can be the other means to get feedback.

\section{B. Reputation Indicator Matrix}

The second component of the framework encompasses the aspects of VO. This component is called the Reputation Indicator matrix. It is identified that in e-commerce form of VO; financial, organizational, operational and third party recommendations are important perspectives that need to be considered while forming $\mathrm{VO}[2]$. Therefore, to establish a 
relationship of deduced Reputation Indicatorswith these perspectives, a Reputation Indicator matrix is developed as shown in Table 2. This matrix identifies all the perspectives that are covered by reputation indicators. These perspectives are Financial, Organizational, Operational, Third party, External and Competency of collaborators, collectively named as FOOTEC. Financial perspective covers the financial soundness. Organizational perspective covers the management system and control of an organization. Functional reliability is covered in Operational perspective. Recommendations about the collaborators are included in Third Party. Factors that are external to the organization are covered in External perspective whereas Competency covers the skills of a collaborator in a particular area of its expertise.

TABLE II. REPUTATION INDICATOR MATRIX

\begin{tabular}{|c|c|c|c|c|c|c|c|}
\hline \multicolumn{2}{|c|}{ Reputation Indicators } & \multicolumn{6}{|c|}{ Type } \\
\hline & & $\mathrm{F}$ & $\mathrm{O}$ & \multirow{2}{*}{$O p$} & \multirow{2}{*}{$\mathrm{T}$} & \multirow{2}{*}{\begin{tabular}{|l}
$E$ \\
$Y$
\end{tabular}} & \multirow{2}{*}{\begin{tabular}{|l}
$\mathrm{C}$ \\
$\mathrm{Y}$
\end{tabular}} \\
\hline \multirow[t]{9}{*}{ Before Disaster } & Standards & & & & & & \\
\hline & Exercises, Drills & & & $\bar{Y}$ & & & $\mathrm{Y}$ \\
\hline & $\begin{array}{c}\text { Workshop, Courses, } \\
\text { Certificates }\end{array}$ & & & & & $\mathrm{Y}$ & $\mathrm{Y}$ \\
\hline & Equipment Certification & & & & & $\bar{Y}$ & \\
\hline & Mutual Aid Agreement & & $Y$ & $\mathrm{Y}$ & & & \\
\hline & $\begin{array}{l}\text { Previous Experience/ } \\
\text { Existing Reputation in the } \\
\text { related field }\end{array}$ & & $\bar{Y}$ & & & & $\mathrm{Y}$ \\
\hline & Operational Resources & $\bar{Y}$ & & & & & $\bar{Y}$ \\
\hline & $\begin{array}{l}\text { Any sort of collaboration } \\
\text { with government/non- } \\
\text { governmental institutions at } \\
\text { local level }\end{array}$ & & 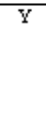 & $\mathrm{Y}$ & & & \\
\hline & Broker Reputation & & $\bar{Y}$ & & $\mathrm{Y}$ & & \\
\hline \multirow{5}{*}{$\begin{array}{l}\text { During and } \\
\text { After } \\
\text { Disaster }\end{array}$} & Timeliness & & & $\mathrm{Y}$ & & & $\mathrm{Y}$ \\
\hline & Operational Cost & & & $\bar{Y}$ & & & $\bar{Y}$ \\
\hline & Feedback & & $\overline{\mathrm{Y}}$ & & $\bar{Y}$ & $\bar{Y}$ & \\
\hline & Peer's Review & & $\bar{Y}$ & $\bar{Y}$ & & & $\bar{Y}$ \\
\hline & DMA Evaluation Reports & $\mathrm{Y}$ & $\mathrm{Y}$ & $\mathrm{Y}$ & & & $\mathrm{Y}$ \\
\hline
\end{tabular}

The RI Matrix facilitates in categorization of the RIs and helps in identifying the relationship of these categories with VO. The computational algorithm helps in quantifying the reputation score hence make the decision making easy and efficient for the relevant authorities. SOA approach for information extraction and exchange fulfills the constraints of integration and interoperability. This issue is further elaborated in Section IV.

\section{Computational Model for Reputation Calculation}

For each collaborator, reputation score of the identified factors is calculated using a computational algorithm that is based on sum and mean model. Sum and mean model is one of the state of the art models for reputation calculation. The algorithm for reputation calculation is shown in Fig 2 .

\section{SOA for Information Extraction}

As the information related to these indicators is held by different systems and stakeholders, information exchange can be difficult. Therefore for integrating heterogeneous systems and multiple sources of information, a Service Oriented Architecture (SOA) is proposed for developing such a reputation management system. The proposed SOA model is shown in the Fig 3. It consists of following three components

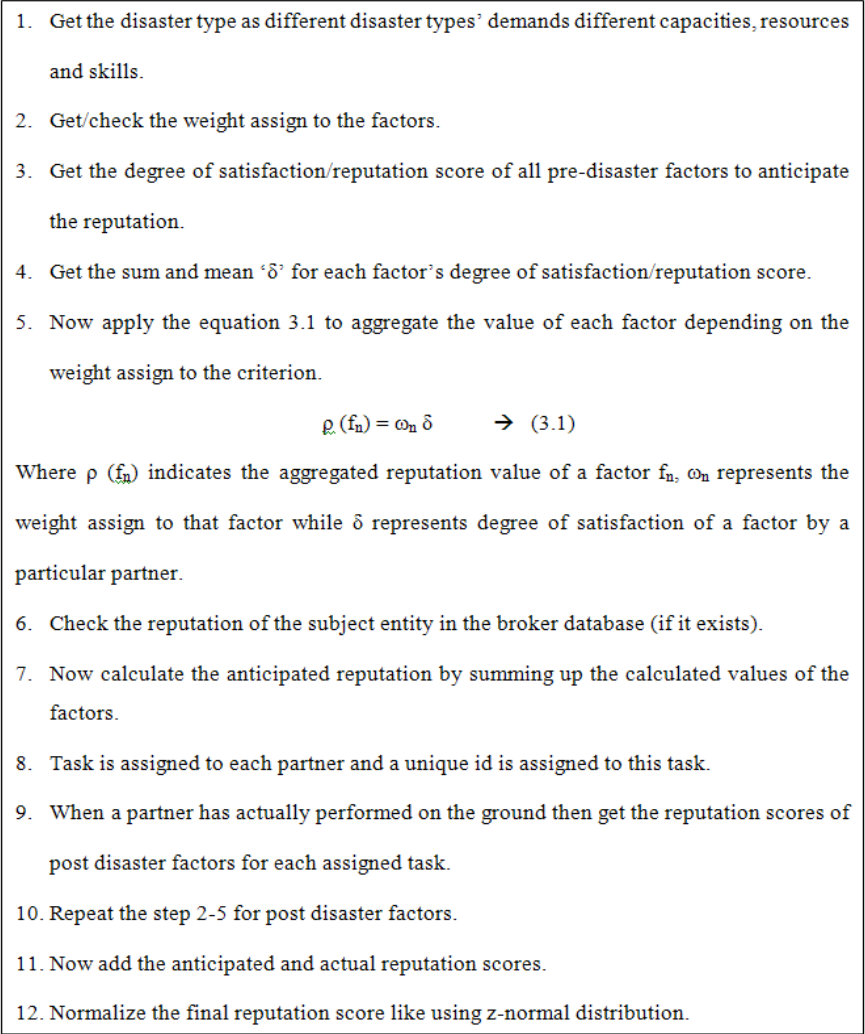

Fig. 2. Algorithm for Reputation Calculation

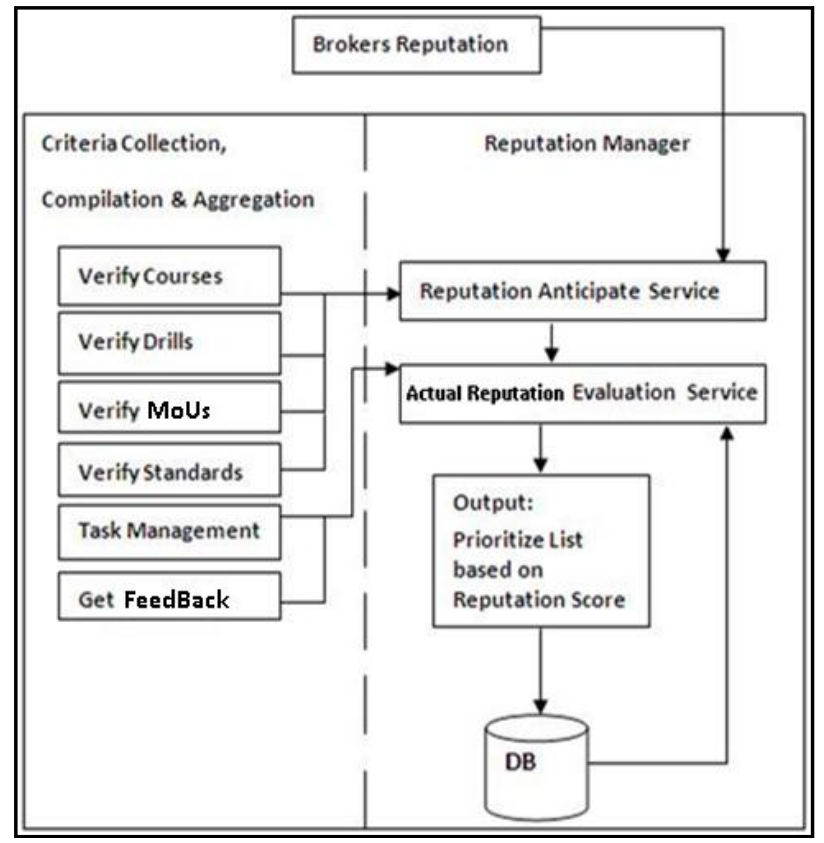

Fig. 3. SOA for Information Extraction and Reputation Calculation

1) Criteria Collection, Compilation and Aggregation: This component collects the feedback score from internal and external sources. The scores are then compiled and aggregated 
to get a cumulative reputation score for different factors. Some web servicesfor the extraction of feedback score are also defined in this component.

2) Reputation Manager: This componentgets the cumulative reputation score of different factors. Mathematical model 1 mentioned in Fig 2 is then applied based on different weights assigned to these factors. This results in a prioritized list of partners based on their reputation score.

3) Broker Reputation: It checks the broker's database for reputation score of the partners

\section{PROTOTYPE IMPLEMENTATION}

For the proof of concept, a prototype is implemented to evaluate the quality and effectiveness of the system in a disaster and emergency situation. Ahypothetical scenario is consideredto simulate a flash-flood situation. Flash flood is a type of flood that develops in few minutes. A web based application is developed to demonstrate the functionalities of our Reputation Management System (RMS). The web application comprises of a number of web services. These services are as follows:

1) Manage Partners

2) Manage Courses/Workshops

3) Manage Drills/Exercises

4) Manage Standards

5) Manage Operation Resources

6) Manage Equipment Certificates

7) Reputation Manager

8) Manage Tasks

With the help of aforementioned hypothetical scenario to handle disaster of flash floods, the usage of RMS is described in three phases while keeping in view the disaster management cycle. First is called Pre-disaster, consisting of preparation and planning; second is called During-disaster encompassing the response phase while recovery and mitigation is merged into third phase named as Post-Disaster.

\section{A. Pre Disaster}

A Disaster Management Agency (DMA) plans and prepares itself for the upcoming rainy season. From experience, the DMA has learnt that extensive rainfall in rainy season causes the flash flood in the low-lying areas which results in severe damages to the affected areas. It is also considered that the DMA was not able to handle such incidents alone. Considering these constraints, the DMA identifies collaborators/partners for relief and rehabilitation purposes. This process of identifying the potential threats of flash flood and based on this, the identification of collaborators is recognized as the identification phase of VO. The administration of the DMA decides to use the RMS for managing and tracking the reputation of these collaborators/partners. For this, the administrator uses the 'add a partner' web service

\section{Manage a Partner Service}

The administrator can add any identified collaborator by entering the following data in the RMS for that collaborator.
- Partner ID:A unique numeric number given to collaborator.

- Partner Name: Name of collaborator

- Competency ID: Competency to be selected from a predefined list; e.g. Shelter Management.

The web interface developed for our application is given in Appendix in Fig A-1.

\section{Manage Courses/Workshops Service}

After assignment of an identity in the RMS, the collaborators use their applications to invoke their relevant web services of the RMS. It is the responsibility of the collaborators to add their data which is related to pre-disaster factors. This includes all the information of courses/workshops, drills/exercises, operational resources and all other pre-disaster factors which the collaborators possess. The interface for insertion of courses/workshops, developed for a collaborator, is shown in the Appendixin Fig A-2. The data required to be entered by collaborator is as follows:

- Course/Workshop ID

- Course/Workshop Name

- Conducting Organization

Similarly, a collaborator can enter data of its other competencies including Drills/Exercises, Standards, Operational Resources and Equipment Certificates. After insertion of pre-disaster data by the collaborators, the administrator of the DMA can assign score to each factor. The web interface is shown in Fig A-3.

\section{B. During Disaster}

During flash floods, thousands of people are evacuated through boats since roads and bridges are destroyed. Displaced people immediately need shelter, food supply and medical services. The DMA initially needs collaborators for the following tasks and missions as shown in Table 3. In this chaotic situation, the evaluation and assessment of potential collaborators is a challenge therefore the DMA uses the RMS for the selection of collaborator. The administrator invokes the Reputation Manager service for getting the prioritize list. While doing this, the DMA is in the 'formation' phase of VO for disaster management. It will be in the 'operational' phase of $\mathrm{VO}$ when tasks are assigned to the partners.

TABLE III. SUMMARY OF TASKS AND MisSIONS

\begin{tabular}{|l|l|}
\hline Missions/ Tasks & Details \\
\hline Required shelters & 30,000 tents \\
\hline Water and food supply & For 50, 000 people \\
\hline Health and medical & For 70, 000 people \\
\hline
\end{tabular}

\section{Reputation Manager Service}

The administrator selects the required competency, assigns weight to pre-disaster factors and then gets a prioritize list of competent partners along with their reputation score in the selected competency. The reputation score is normalized on the scale of 1 to 10 . The interface for the reputation manager service is shown in Fig A-4 in Appendix A. 


\section{Manage Tasks Service}

Based on the prioritize list, the administrator selects the collaborator and assigns the tasks by invoking 'assigning a task' service. For the purpose of assigning a task, the administrator only enters the relevant information in the RMS to track the record in future. The interface, for this purpose, is shown in the Fig A-5 in Appendix A.

\section{Post Disaster}

Recovery and mitigation phases start after the response phase. In these phases, the RMS collects, aggregates and compiles the task-based feedback about different collaborators. When the task is finished, team is dissolved that shows the dissolution phase of VO. Firstly, the administrator of DMA evaluates the collaborators' performance based reputation by considering timeliness and operational cost. For this, the administrator assigns task-wise score to each collaborator. The interface for this purpose is shown in the FigA-6 in Appendix-A.

Peers also assess their partners as they have worked on ground with their partners/collaborators. Peers can invoke peers feedback service. The feedback is given for the task in which they have coordinated and collaborated. The interface for this purpose is shown in Fig A-7 in Appendix-A.

\section{RESULTS AND SURVEY}

An online survey was conducted for getting feedback on the proposed framework. Thirty national and international organizations involved in disaster management were contacted. Positive response was received from six organizations who agreed to participate in the survey. These organizations include Pakistan's national organizations as well as international organizations having offices in Pakistan. These organizations include United Nations Development Program (UNDP), NDMA, Engineering Directorate, Earthquake Rehabilitation and Reconstruction Authority (ERRA), Focus and Concern. The survey consisted of a questionnaire form having one open-ended and nine closedended questions. The closed-ended question used different scale for getting the feedback about the extracted factors and the overall framework. The questions, their results and analysis of each question are shown graphically in this section. Different scales are used which are mentioned with each question.

Q1. How significant is the reputation of a partner/member organization for various disaster management activities (preand post disaster operations)?

Fig 4 illustrates that $100 \%$ participants considered the reputation of a partner as 'extremely important'. This undisputed response from the participants substantiates the idea of the current research.

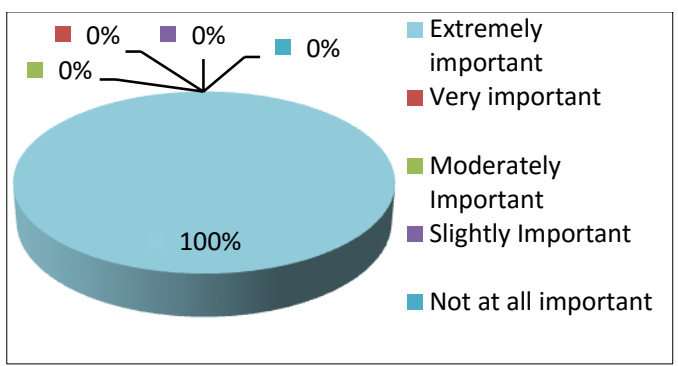

Fig. 4. Significance of Collaborators' Reputation

Q2. How often do you check or assess the reputation of your potential partners before doing any sort of collaboration with them?

Fig 5 reveals that $83 \%$ participants assess the reputation of their potential partners every time whereas $17 \%$ assess it very often. This response supports our background study in which it was identified that stakeholders involved in disaster management realize the value of reputation of the collaborators.

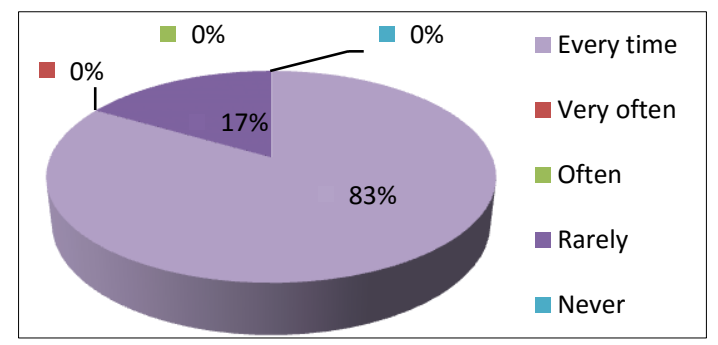

Fig. 5. Evaluation of Collaborators' Reputation

Q3. Does your organization follow any established policy/mechanism for checking/evaluating potential members/partners before doing any kind of collaboration for disaster operations?

It is exposed from the participants of the survey that their organizations have a policy/mechanism for checking/evaluating potential partners as shown in Fig 6. 83\% participants informed that they have well-established mechanism for evaluating the partners whereas $17 \%$ respondents said they have a mechanism but not wellestablished. However, the participants were unwilling to expose their mechanisms due to restrictions of the rules and regulations of their organizations.

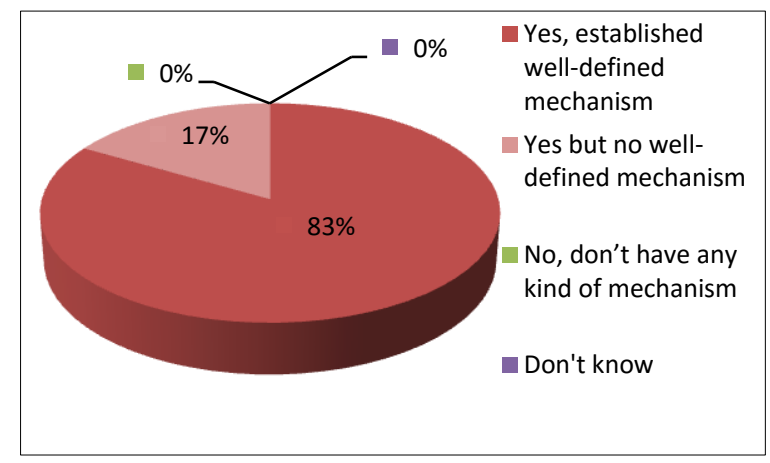

Fig. 6. Presence of Reputation Management Mechanism 
Q4. In your opinion, managing the reputation and trust at three hierarchical levels (i.e. strategic, operational and tactical) is:

Figure 7 shows that the respondents evaluated the idea of managing the reputation, at three hierarchical level, as important. 50\% considered it as extremely important, $33 \%$ as very important while $17 \%$ considered it as moderately important.

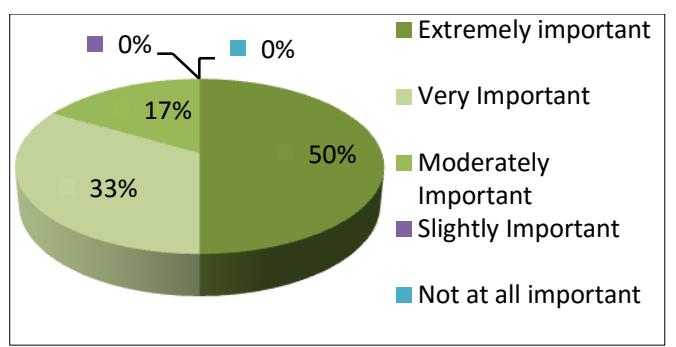

Fig. 7. Reputation Management at Three Hierarchical Levels

Q5. Classification of reputation factors into 'Pre- Disaster' and 'During \& Post Disaster' operations is:

Fig 8 shows that $50 \%$ respondents evaluated our idea of dividing the extracted factors/indicators into two categories as 'absolutely appropriate' whereas $50 \%$ evaluated it as 'appropriate'. In short, all supported this idea of classification.

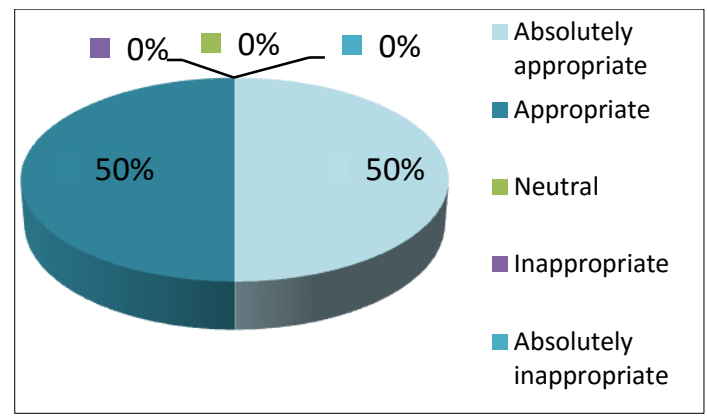

Fig. 8. Importance of Reputation Indicators' Classification

Q6. Please rate the following factors based on their helpfulness in reputation assessment. 1 represents 'extremely unhelpful', 2 represent 'moderately unhelpful', 3 represents neither 'unhelpful' nor 'helpful', 4 represents 'moderately helpful' and 5 represents 'extremely helpful'

The purpose of this question was to evaluate the relevance of extracted factors while evaluating the reputation of the collaborators/partners. The results are shown in Table 4 and 5 with respect to two groups defined in meta model.

Q7. How much weight (based on importance), would you like to give these factors to calculate overall trust/reputation of a member/partner organization?

To evaluate the helpfulness of each factor, three groups are defined based on the results of question 6 and the response of this question. Every group has its own criteria for the insertion in this group. The criteria are shown in Table 4.

TABLE IV. CRITERIA FOR PRIORITIZE GROUPS

\section{Group} Criteria

\begin{tabular}{|l|l|}
\hline High-priority & $\begin{array}{l}\text { got more than } 80 \% \text { votes as 'extremely helpful' } \\
\text { does not get any vote of neither a) 'neither helpful nor } \\
\text { helpfulness' nor b) below this scale }\end{array}$ \\
\hline Medium-priority & $\begin{array}{l}\text { votes of either a) 'extremely helpful' or b) 'moderately } \\
\text { helpful' }\end{array}$ \\
\hline Low-priority & $\begin{array}{l}\text { a vote of 'neither helpful nor unhelpful' is casted but no } \\
\text { vote below this scale }\end{array}$ \\
\hline Drop-out & $\begin{array}{l}\text { get more than 50\% of either a) 'neither helpful nor } \\
\text { unhelpful' or b) below }\end{array}$ \\
\hline
\end{tabular}

TABLE V. CATEgorizATION AND RANKING OF FACTORS IN PRIORITY GROUPS

\begin{tabular}{|c|c|c|c|c|}
\hline Group & Rank & Factor's Name & Category & $\begin{array}{l}\text { Average } \\
\text { Weight }\end{array}$ \\
\hline \multirow{5}{*}{$\begin{array}{l}\text { High- } \\
\text { priority } \\
\text { group }\end{array}$} & \multirow{3}{*}{$1^{\mathrm{st}}$} & Broker Reputation & Pre-disaster & 5 \\
\hline & & Previous Experience & Pre-disaster & 5 \\
\hline & & Community Feedback & $\begin{array}{l}\text { Post- } \\
\text { disaster }\end{array}$ & 5 \\
\hline & $2^{\text {nd }}$ & Timeliness & $\begin{array}{l}\text { Post- } \\
\text { disaster }\end{array}$ & 4.8 \\
\hline & $3^{\text {rd }}$ & Standards & Pre-disaster & 4.7 \\
\hline \multirow{5}{*}{$\begin{array}{l}\text { Medium- } \\
\text { priority } \\
\text { group }\end{array}$} & \multirow{3}{*}{$1^{\mathrm{st}}$} & Exercises/Drills & Pre-disaster & 4.5 \\
\hline & & Operational Resources & Pre-disaster & 4.5 \\
\hline & & Courses/Workshops & Pre-disaster & 4.5 \\
\hline & \multirow[b]{2}{*}{$2^{\text {nd }}$} & Local Collaboration & Pre-disaster & 4.2 \\
\hline & & Peer's Review & $\begin{array}{l}\text { Post- } \\
\text { disaster }\end{array}$ & 42 \\
\hline \multirow{7}{*}{$\begin{array}{l}\text { Low- } \\
\text { priority } \\
\text { group }\end{array}$} & \multirow{2}{*}{$1^{\mathrm{st}}$} & Donor's Feedback & $\begin{array}{l}\begin{array}{l}\text { Post- } \\
\text { disaster }\end{array} \\
\end{array}$ & 4.5 \\
\hline & & Operational Cost & $\begin{array}{l}\text { Post- } \\
\text { disaster }\end{array}$ & 4.6 \\
\hline & \multirow[t]{2}{*}{$2^{\text {nd }}$} & Surveys & $\begin{array}{l}\text { Post- } \\
\text { disaster }\end{array}$ & 4.3 \\
\hline & & Equipment Certificates & Pre-disaster & 4.3 \\
\hline & $3^{\text {rd }}$ & MoUs/MAAs & Pre-disaster & 4.2 \\
\hline & $4^{\text {th }}$ & DMA Report & $\begin{array}{l}\text { Post- } \\
\text { disaster }\end{array}$ & 4 \\
\hline & $5^{\text {th }}$ & Media & $\begin{array}{l}\text { Post- } \\
\text { disaster }\end{array}$ & 3.7 \\
\hline Drop-out & -- & SMS Feedback & $\begin{array}{l}\text { Post- } \\
\text { disaster }\end{array}$ & - \\
\hline
\end{tabular}

Based on these criteria, Table 5 shows the ranking of each factor along with the average weight assigned by the respondents to each factor.

Q8. Would you like to suggest any new factor which can help in assessing the reputation of a partner? Please also describe the reason.

The respondents' suggestions along with the remarks on the suggestions are shown in Table 6.

TABLE VI. SUGGESTIONS FROM RESPONDENTS

\begin{tabular}{|l|l|}
\hline Suggestions & Remarks \\
\hline Staff competency and aptitude & $\begin{array}{l}\text { A detailed discussion, with the } \\
\text { respondent, was carried out } \\
\text { regarding this suggestion. He } \\
\text { agreed that }\end{array}$ \\
\hline No & $\begin{array}{l}\text { The respondent was satisfied with } \\
\text { the deduced factors. }\end{array}$ \\
\hline $\begin{array}{l}\text { Partners style of data management and } \\
\text { reporting is very much important }\end{array}$ & $\begin{array}{l}\text { This suggestion is point towards } \\
\text { standardized data management } \\
\text { and reporting which has been } \\
\text { covered in the pre-disaster factor } \\
\text { i.e. standards }\end{array}$ \\
\hline $\begin{array}{l}\text { The factors identified are all- } \\
\text { encompassing. However, one might }\end{array}$ & $\begin{array}{l}\text { This suggestion points towards } \\
\text { the standards a collaborator is }\end{array}$ \\
\hline
\end{tabular}




\begin{tabular}{|l|l|}
\hline $\begin{array}{l}\text { add information management systems, } \\
\text { reporting mechanisms and quality } \\
\text { control / monitoring and evaluation } \\
\text { capacity as one additional factor }\end{array}$ & following. \\
\hline $\begin{array}{l}\text { Community awareness and } \\
\text { involvement in all kind of DRR and } \\
\text { DRM activities }\end{array}$ & $\begin{array}{l}\text { Community involvement is being } \\
\text { done through feedback and } \\
\text { awareness through } \\
\text { courses/workshop and } \\
\text { drills/exercises. }\end{array}$ \\
\hline
\end{tabular}

Q9. Do you think a combination of Information Technology and people's activities in disaster response operations can play an important role in managing reputation and trust of involved organizations?

$50 \%$ participants, in response to this question voted for 'extremely helpful', 33\% supported it as 'very important' whereas $17 \%$ evaluated it as 'moderately important' as shown in Fig 9. Such a response from the participants depicts that the introduction of ICT-based solution for reputation based trust management will be helpful for the stakeholders involved in disaster management.

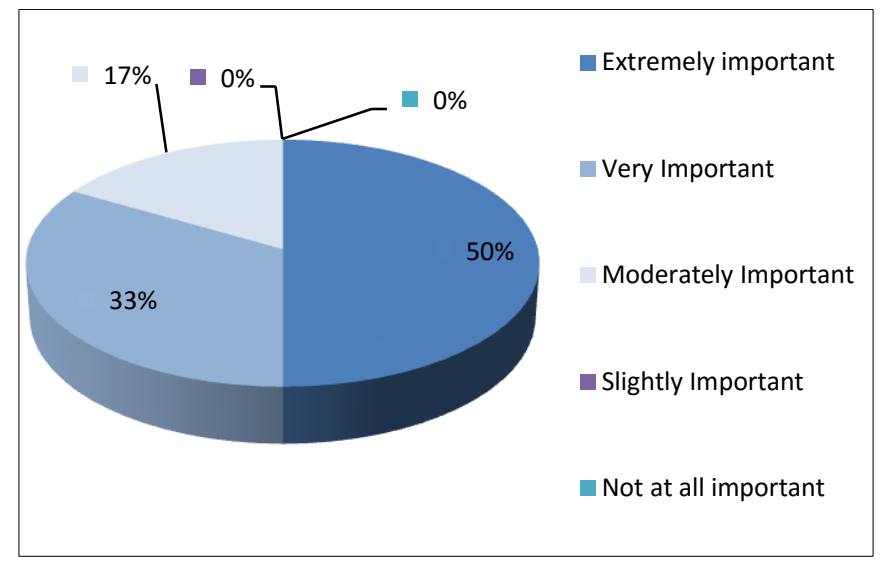

Fig. 9. Importance of Information System for Reputation Management

Q10. Do you agree that the integration of existing Information Systems of participating organizations and/or development of Online Integrated Information Services for disaster response organizations can be helpful in trust/reputation management?

All participants were agreed for introducing the IT standards in the integration of reputation management system with the legacy system of disaster management organizations as shown in Fig 10.

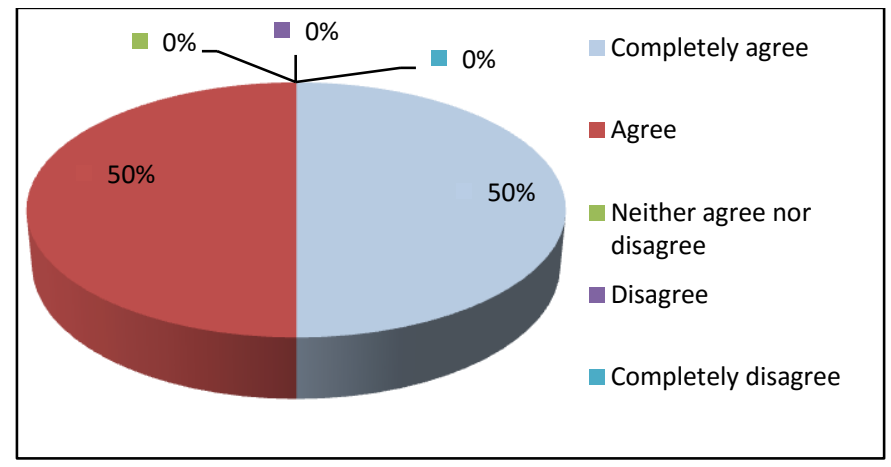

Fig. 10. Need of Online Integrated System

\section{CONCLUSION}

This research presents a substantial base for reputation management of collaborators involved in disaster management. Keeping in view, the state of the art approach for reputation management in different domains, multi-criteria reputation assessment and an aggregation model for reputation calculation are proposed. The multi-criteria of the proposed framework illustrate the priorities of disaster management's stakeholders. These are the characteristics that are expected to be present in the collaborators hence help in establishing the reputation of the collaborators. The aggregation model helps in quantifying the reputation score in such a manner that decision making becomes easy and efficient for the relevant authorities.

The applicability of the proposed framework is evaluated through prototype implementation. It is evident from the prototype that information exchange among heterogeneous systems is not problematic hence multi-criteria monitoring is made possible for the stakeholders of disaster management. Besides this, the survey results show substantial support from the participant organizations.

Collaborators often fail in performing their duties while managing disasters. It is concluded that the reputation management system acts as a silent observer of their reputation and helps the authorities in smart decision making for disaster management. This research contribution can be refined by introducing risk management aspect in the framework hence the basis for reasoning about the involved risk (while selecting collaborators) can be presented. Moreover, information extraction (about reputation of collaborators) from media reports and social networks can also be searched semantically which can help in being more transparent.

\section{REFERENCES}

[1] F. Ye and G. Li, "Study on virtual organization product development based on total lifecycle agile manufacturing in the networked collaborative environment," in Technology and Innovation Conference, 2006. ITIC 2006. International, 2006, pp. 556-561.

[2] T. J. Winkler, J. Haller, H. Gimpel, and C. Weinhardt, "Trust Indicator Modeling for a Reputation Service in Virtual Organizations," in ECIS, 2007, pp. 1584-1595.

[3] M. Careem, C. De Silva, R. De Silva, L. Raschid, and S. Weerawarana, "Sahana: Overview of a disaster management system," in Information and Automation, 2006. ICIA 2006. International Conference on, 2006, pp. 361-366.

[4] O. Konsortium, "OASIS project Executive Summary," ed, 2005.

[5] M. Deutsch, "Cooperation and trust: Some theoretical notes," 1962.

[6] S. Hall and W. McQuay, "Review of trust research from an interdisciplinary perspective-psychology, sociology, economics, and cyberspace," in Aerospace and Electronics Conference (NAECON), Proceedings of the IEEE 2010 National, 2010, pp. 18-25.

[7] K.-J. Lin, H. Lu, T. Yu, and C.-e. Tai, "A reputation and trust management broker framework for web applications," in e-Technology, e-Commerce and e-Service, 2005. EEE'05. Proceedings. The 2005 IEEE International Conference on, 2005, pp. 262-269.

[8] J. Lee and K.-J. Lin, "Context-aware distributed reputation management system," in e-Business Engineering, 2008. ICEBE'08. IEEE International Conference on, 2008, pp. 61-68.

[9] M. J. Gallivan, "Striking a balance between trust and control in a virtual organization: a content analysis of open source software case studies," Information Systems Journal, vol. 11, pp. 277-304, 2001. 
[10] O. Hasan, "Privacy preserving reputation systems for decentralized environments," Thse de doctorat en informatique, INSA de Lyon (Sep. 2010), 2010.

[11] G. Linden, B. Smith, and J. York, "Amazon. com recommendations: Item-to-item collaborative filtering," Internet Computing, IEEE, vol. 7, pp. 76-80, 2003.

[12] R. Zolin, "Swift trust in hastily formed networks," DTIC Document2002.

[13] T. L. Currao, "A new role for emergency management: fostering trust to enhance collaboration in complex adaptive emergency response systems," DTIC Document2009.

[14] Østensvig, "Interagency cooperation in disaster management: partnership, information and communications technology and committed individuals in Jamaica," Masters thesis at the Norwegian University Of Life Sciences, Ås, Norway. At http://www. islandvulnerability. org/caribbean. html\# jamaica, 2006.

[15] Eryilmaz, M. Cochran, and S. Kasemvilas, "Establishing trust management in an open source collaborative information repository: An emergency response information system case study," in System Sciences, 2009. HICSS'09. 42nd Hawaii International Conference on, 2009, pp. 1-10.

[16] M. Couturier and E. Wilkinson, "Open advanced system for improved crisis management (OASIS)," in Proceedings of the 2nd International Information Systems for Crisis Response and Management (ISCRAM) Conference, Brussels, Belgium, 2005.

[17] Henriques and D. Rego, "OASIS Tactical Situation Object: a route to interoperability," in Proceedings of the 26th annual ACM International Conference on Design of Communication, 2008, pp. 269-270.

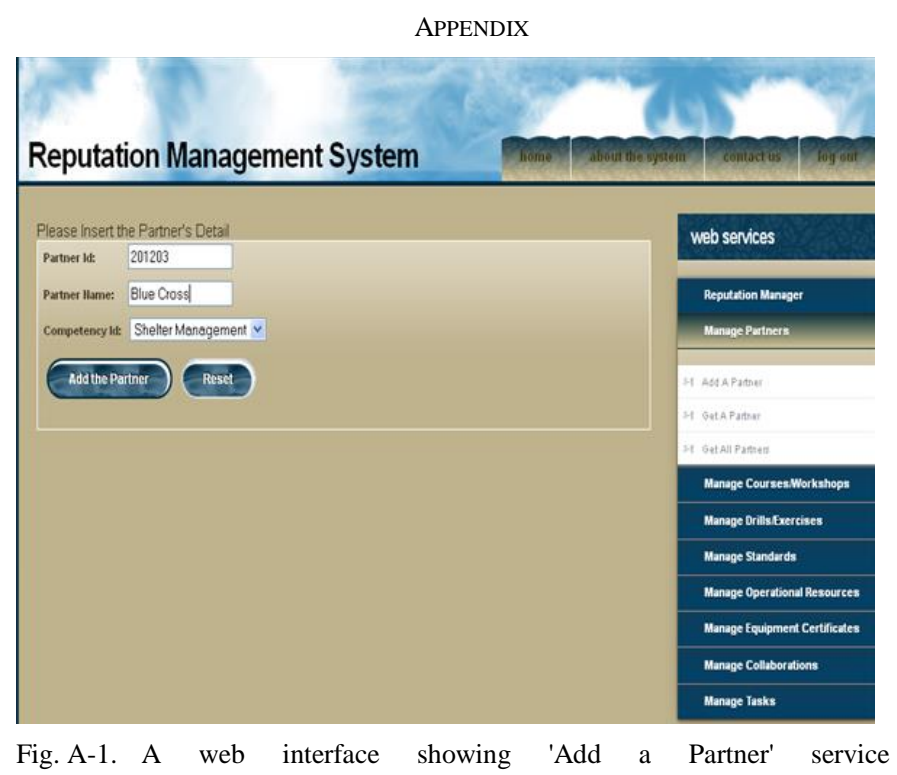




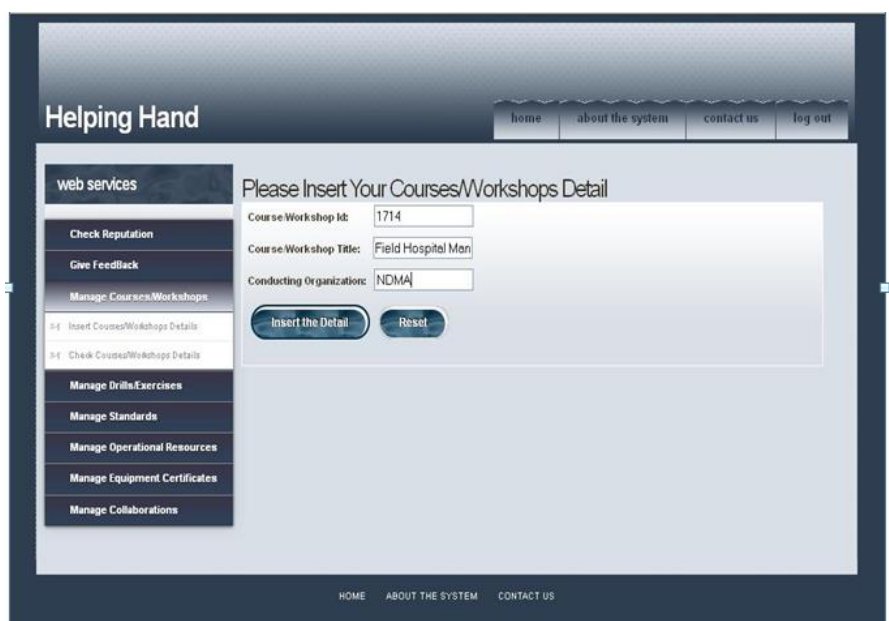

Fig. A-2. A web interface for collaborators where they can Insert Courses/Workshop Data

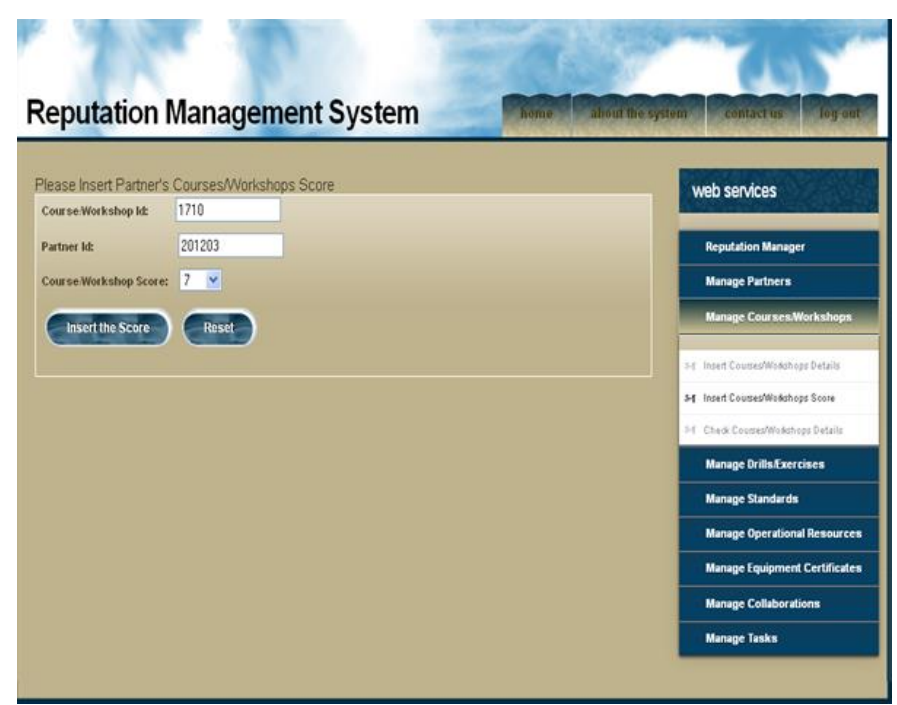

Fig. A-3. Disaster Management Agency can assign Reputation Score to Collaborator's Course/Workshop

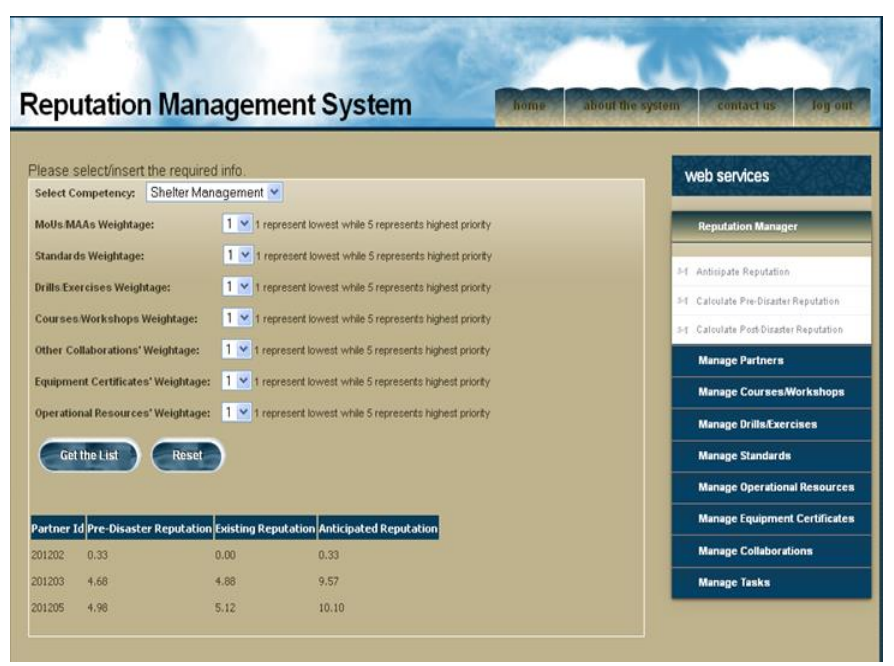

Fig. A-4. Administrator can enter weights for different factors. Based on these values, a Prioritize List of partners is generated based on Reputation Score

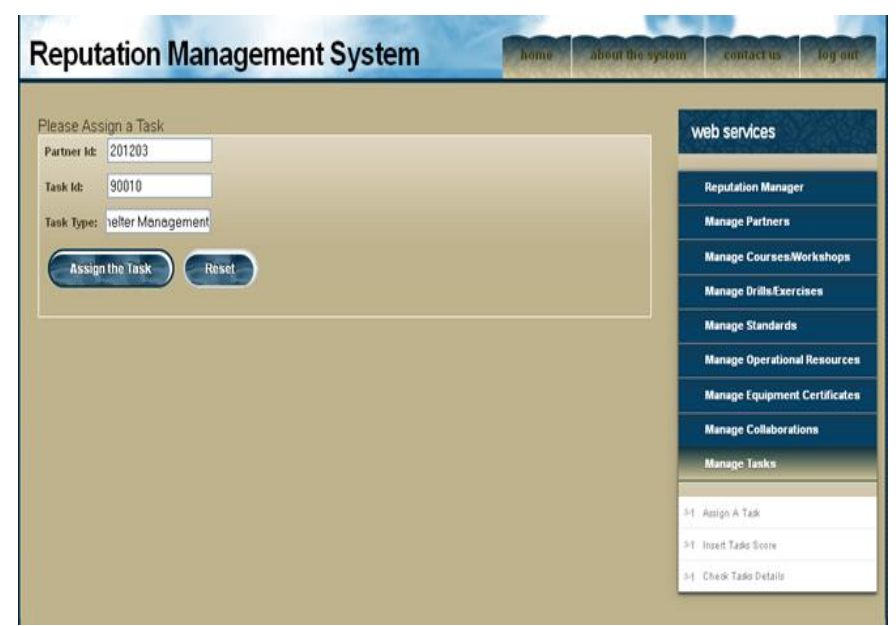

Fig. A-5. A web interface of 'Assign Task to a Collaborator' service

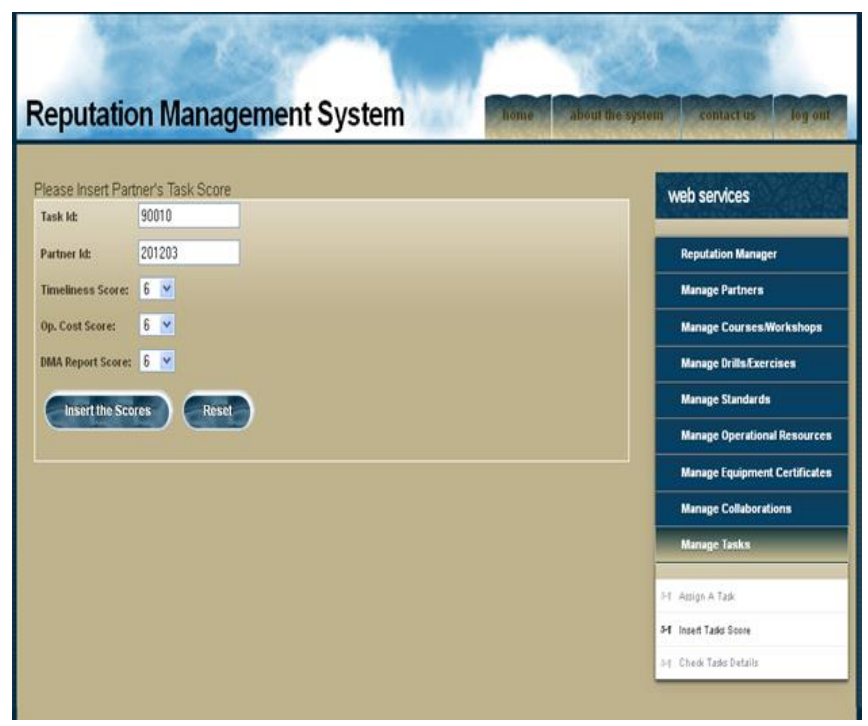

Fig. A-6. A web interface for admin to enter 'Task Score' to different collaborators in Post-Disaster phase

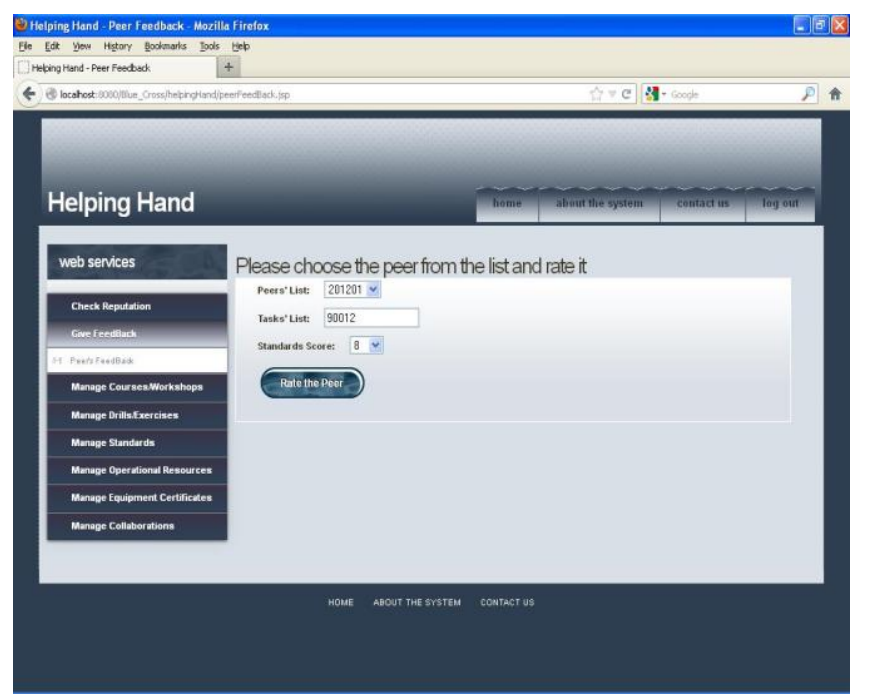

Fig. A-7. Peer's Feedback 